Aim of the study: The aim of this study was to examine the relationship between religiosity, mental health, and psychological resilience in breast cancer patients.

Material and methods: A crosssectional study was conducted in an oncology department of a hospital in northern Greece during February and March 2017. The sample consisted of 152 breast cancer patients. Data were collected with the following instruments: Patient Health Questionnaire two-item scale, Generalised Anxiety Disorder two-item scale, ConnorDavidson Resilience Scale 25, and Centrality of Religiosity Scale. Also, patients' characteristics were included, specifically demographic, social, and clinical information. Statistical analyses were conducted with the Statistical Package for the Social Sciences V25.

Results: According to our results, approximately 1 out of 3 patients had depression and anxiety. Also, the sample had moderate resilience and were moderately religious. Patients who were classified as end-stage cancer patients and those who underwent mastectomy found to be more religious. Religiosity correlated positively with the resilience, while no correlation was found with depression, anxiety, and symptom burden. Based on regression results, religious beliefs seem to be a predictive factor for resilience and resilience is a predictive factor for depression.

Conclusions: Our findings show that there was no association between religiosity and mental health, while a strong relation was highlighted between religious beliefs and psychological resilience. This study should constitute a starting point for further assessments regarding the fact that religiosity can provide social support that facilitates psychological adaption to illness and helps cancer patients to cope with their illness, which should be recognised by health care professionals.

Key words: religiosity, breast cancer psychological resilience, depression, anxiety.

Contemp Oncol (Pozn) 2018; 22 (3): 172-177 DOI: https://doi.org/10.5114/wo.2018.78947

\section{Assessment of the relation between religiosity, mental health, and psychological resilience in breast cancer patients}

\author{
Evangelos C. Fradelos ${ }^{1}$, Dimitra Latsou ${ }^{2}$, Dimitroula Mitsi ${ }^{3}$, \\ Konstantinos Tsaras ${ }^{4}$, Dimitra Lekka ${ }^{1}$, Maria Lavdaniti $^{5}$, Foteini Tzavella ${ }^{6}$, \\ Ioanna V. Papathanasiou ${ }^{4}$
}

\author{
'Psychiatric Department, “Sotiria” Athens General Hospital for Chest Diseases, Athens, \\ Greece \\ ${ }^{2}$ Department of Social and Educational Policy, University of Peloponnese, Corinth, \\ Greece \\ "Athens General Hospital "Elpis", Athens, Greece \\ ${ }^{4}$ Department of Nursing, Technological Educational Institute of Thessaly, Larissa, Greece \\ 'Department of Nursing, Technological Educational Institute of Thessaloniki, \\ Thessaloniki, Greece \\ ${ }^{6}$ Department of Nursing, University of Peloponnese, Sparta, Greece
}

\section{Introduction}

Breast cancer is a major health problem specially for women living in developed countries. It is estimated that it accounts for nearly $30 \%$ of total cancer incidence in USA and is the cause of $17 \%$ of all cancer deaths [1], and breast cancer is the most frequent cause of death for women aged from 35 to 45 years. In addition, in northern Europe and America, the incidence of breast cancer is around 100 cases per 100,000 women per year and the lifetime probability of illness is 1 in 9 [2].

To be diagnosed with breast cancer and undergo mastectomy and chemotherapy can induce a lot of stress. In addition, breast cancer patients can experience various mental health issues such as depression and anxiety [3]. Psychological resilience is the ability that a person has to protect him/herself and his/her mental health in times when dealing with life adversities, such a breast cancer diagnosis [4]. Over the years various ways have been suggested to approach and understand resilience. Literature argues that there is a personality trait that enables individuals to maintain mental health while experiencing life difficulties, while others suggest that resilience is an adapting mechanism that helps individuals to adapt to new situations and protect their mental health [4]. Nonetheless, resilience can be a valuable resource in coping with breast cancer; it is considered as a multidimensional process which contains among others a natural interaction of attributes [5].

Another psychosocial aspect often neglected during breast cancer care is religiosity, which has been recognised as a relevant factor in this group of patients [6]. Despite this assumption and the increasing research interest in the relationship of religiosity with psycho-cynic parameters in various diseases, this issue remains controversial. A recent cross-sectional study showed no association between religiosity and depression [7]. A similar finding was reported by other study with 200 individuals who were dealing with mood disorders. Particularly in the above-mentioned study, religiosity had only a minor impact on psychopathological symptoms, and only a significant negative correlation with suicidal ideation/behaviour emerged [8]. On the other hand, there are many studies suggesting that religion and spirituality can play an important role in coping with cancer, protecting mental health, and improving quality of life. Moreover, religious/spiritual coping is consider- 
ing to be an important strategy, especially during the time that patients receive chemotherapy [9-11]. According to Kasen et al., individuals' religiosity, spirituality, and attendance to religious services can be beneficial and protective factors and can enhance the resilience in individuals who at high risk of depression [12]. Religion and religiosity are often associated with the experience and expression of positive emotions such as hope [13]. In addition, organised religion can be a system that gives meaning in one's life, especially during stressful events. That is why region and religiosity can enhance resilience, facilitating the individuals with values to maintain a positive perspective in life's adversities [14].

Although a considerable number of articles on breast cancer have been published, few studies have examined religiosity, mental health, and resilience, but to the best of our knowledge no research has been conducted in Greece. Furthermore, relevant studies in international literature have produced mixed findings. Consequently, the assessment of the current issue needs to be better understood and addressed more fully in breast cancer patients.

The aim of this study is to investigate religiosity in Greek breast cancer patients, as well as the effect that it might have on mental health and psychological resilience.

\section{Material and methods}

\section{Study design and sample}

This cross-sectional study was conducted in the oncology department of a hospital in northern Greece between February and March 2017. The oncology department is an important provider of breast cancer services to people in northern Greece. Women who visited the hospital for follow-up after mastectomy or lumpectomy were recruited to participate in the study. Subjects were eligible for study participation if they were 18 years old or above, had undergone breast surgery, were able to communicate in Greek language and had sufficient cognitive ability to participate in the study.

All eligible participants provided written, informed consent before completing a structured questionnaire. Initially, a total of 180 patients were recruited, of whom 164 completed and submitted the questionnaire. Twelve patients were excluded from analysis because of incomplete data. Final analysis was based on the remaining 152 questionnaires. This study meets the ethics guidelines of the hospital where the study was performed.

\section{Instruments}

Data on sociodemographic and psychological variables were collected to investigate the relationships between psychological conditions and dealing with breast cancer treatment. Participants answered the following questionnaires:

Depression was measured with the Patient Health Questionnaire two-item depression scale (PHQ-2). This instrument is a short form of PHQ-9, of which the first two questions have been shown to have good sensitivity for identifying cases of depression at a score of $\geq 3$ (range 0-6) [15]. On the PHQ-2 patients indicate the frequency with which they have been bothered by two problems in the past two weeks: 0 ("not at all"), 1 ("several days"), 2 ("more than half the days"), and 3 ("nearly all the time"). Scores of more than 3 represent severe depression [16, 17].

The Generalised Anxiety Disorder two-item scale (GAD-2) has two items with response options identical to the PHQ-2 and can be scored from 0 to 6 (with higher scores representing more severe anxiety). The questionnaire was originally developed as a measure to detect generalised anxiety disorder [18]. Also, the GAD-2 evaluates other common anxiety disorders in clinical practice: panic disorder, social anxiety disorder, and posttraumatic stress disorder [19].

Psychological resilience was assessed using the ConnorDavidson Resilience Scale 25 (CD-RISC 25) [20, 21]. This questionnaire provides a unidimensional measure reflecting the ability to bounce back from a variety of challenges such as illness, emotional pressure or painful feelings. Items are rated on a five-point scale (from 0 - "not true at all" to 4 - "true nearly all the time") providing a total sum score ranging from $0-100$, with higher scores reflecting greater resilience.

Religiosity was assessed using the Centrality of Religiosity Scale (CRS) which consists of 15 items (CRS-15) [22]. The scale consists of five dimensions: public practice, private practice, religious experience, ideology and intellectual interest (three questions for each). Participants are asked to rate items on a five-point Likert scale ranging from "not at all" to "very much". The Greek version of the instrument was used in this study. The Greek validation study concludes in two factor solutions, one measuring religious beliefs and experiences and the second measuring religious practices [23].

Moreover, patients completed their sociodemographic and clinical characteristics, such as: age, living arrangement, number of children, educational level, type of surgery, stage of cancer, adjuvant therapy, and symptom burden.

\section{Statistical analyses}

Descriptive statistics were used to assess sample characteristics, psychological variables, and religiosity. Normality was first tested for each variable. For the comparison of proportions, the $\chi^{2}$ test was used. Independent-sample t-test and one-way analysis of variance were conducted to compare the means of resilience and religiosity for categorical variables. Spearman correlation coefficient was used to identify the relationship between the examined variables, and multiple linear regression analysis with backward method was applied to identify the predictors of resilience. Also, logistic regression analyses were performed in order to observe changes in depression and anxiety of cancer patients. Statistical analyses were conducted with Statistical Package for the Social Sciences, version 25.0. Significance for all statistical tests was set at 0.05 or less (two-tailed).

\section{Results}

Demographic characteristics of patients are shown in Table 1. The participants ranged in age from 27 to 87 years (mean $\pm \mathrm{SD}=53.2 \pm 12$ ). The median age was 53 years. $55.3 \%$ of the participants were married, and the remainder 
Table 1. Demographic and clinical characteristics of participants

\begin{tabular}{|c|c|c|c|}
\hline Characteristic & & $\begin{array}{l}\text { Number } \\
(n)\end{array}$ & $\begin{array}{l}\text { Percentage } \\
\text { (\%) }\end{array}$ \\
\hline \multirow[t]{5}{*}{ Age group } & Below 40 & 25 & 16.9 \\
\hline & $41-50$ & 34 & 23 \\
\hline & $51-60$ & 47 & 31.8 \\
\hline & $61-70$ & 35 & 23.6 \\
\hline & $71+$ & 7 & 4.7 \\
\hline \multirow[t]{2}{*}{ Living arrangement } & Living with family & 84 & 55.3 \\
\hline & Living alone & 68 & 44.7 \\
\hline \multirow[t]{5}{*}{ Number of children } & 0 & 32 & 21.1 \\
\hline & 1 & 23 & 15.1 \\
\hline & 2 & 62 & 40.8 \\
\hline & 3 & 32 & 21.1 \\
\hline & 4 & 3 & 2 \\
\hline \multirow[t]{4}{*}{ Educational level } & Primary & 31 & 20.4 \\
\hline & Secondary & 67 & 44.1 \\
\hline & Tertiary & 53 & 34.9 \\
\hline & Master/PhD & 1 & 0.7 \\
\hline \multirow[t]{2}{*}{ Type of surgery } & Mastectomy & 107 & 70.4 \\
\hline & Lumpectomy & 45 & 29.6 \\
\hline \multirow[t]{2}{*}{ Stage of cancer } & Initial & 68 & 45 \\
\hline & Advanced & 83 & 55 \\
\hline \multirow[t]{3}{*}{ Adjuvant therapy } & $\begin{array}{l}\text { Surgery and } \\
\text { chemotherapy }\end{array}$ & 72 & 47.4 \\
\hline & $\begin{array}{l}\text { Surgery and } \\
\text { radiotherapy }\end{array}$ & 23 & 15.1 \\
\hline & $\begin{array}{l}\text { Surgery, } \\
\text { chemotherapy, } \\
\text { and radiotherapy }\end{array}$ & 57 & 37.5 \\
\hline
\end{tabular}

lived alone. $44.1 \%$ received middle school education. In relation to clinical variables, the majority of patients (70.4\%) had undergone mastectomy. $55 \%$ of female subjects was diagnosed at advanced stage, and $47.5 \%$ received surgery and chemotherapy as adjuvant therapy.

Figure 1 presents the symptom burden of patients. The majority (35.5\%) stated that they had some symptoms but did not require bed rest during the day. Also, a high percentage of patients (32.2\%) stated that they had no symptoms and were able to do all their daily activities.

Depression based on PHQ- $2 \geq 3$ was screened in 38.2\% and anxiety by the GAD- $2 \geq 3$ was screened in $32.2 \%$. However, $\mathrm{PHQ}-2 \geq 3$ was not screened in 94 cases $(61.8 \%)$ and GAD-2 $\geq 3$ in 103 cases (67.8\%). Also, the mean score for resilience of breast cancer patients was $65.5 \pm 19$, meaning a moderate resilience and range from 14 to 100 . The results of religiosity are presented in Figure 2 . The mean CRS score was $2.3 \pm 0.5$, ranging from 1 to 3 .

Additionally, statistically significant differences were found between family status, PHQ-2, and GAD-2. Specifically, $58.6 \%$ and $57.1 \%$ of patients who lived alone stated that they had depression and anxiety, respectively, in contrast with the $41.4 \%$ and $42.9 \%$ who lived with their family
( $p=0.007, p=0.034$, respectively). The CRS-score is different between stages of cancer; patients in advanced stage were more likely to be religious than patients in initial stage. Moreover, religiosity seems to be different between types of surgery; patients who had undergone mastectomy were more religious (Table 2 ).

Correlations of the variables, shown in Table 3, indicate a high association between depression and anxiety. The symptom burden has a low correlation with depression and anxiety. Additionally, a moderate negative correlation exists between depression, anxiety, and symptom burden. The religiosity of the sample also correlated positively with the resilience. Conversely, scores on the CRS did not correlate with the depression, anxiety, and symptom burden.

Multiple backward regression analysis was conducted to identify the predictors of resilience. Variables were included in the regression analysis consisting of score of total religiosity, two dimensions (religious practices and religious beliefs), and symptom burden. Finally, as shown in Table 4 the variables included into the regression model were symptom burden $(\beta=-7,269, p \leq 0.001)$ and religious beliefs $(\beta=4,437, p \leq 0.001)$.

Furthermore, the results of the binary logistic regression analysis indicate that the depression was significantly associated with resilience, stage of cancer, and anxiety (Table 5). For every unit increase in resilience, the likelihood of being depressed was reduced by 0.9. Patients in advanced stage were more likely to be depressed by a factor of 3.6. Anxious patients were more likely to be depressed by a factor of 67.8 .

Also, anxiety was significantly associated with symptom burden and depression (Table 6). For every unit increase in symptom burden, the likelihood of being anxious was increased by a factor of 2.1. Depressed patients were more likely to be anxious by a factor of 67.3.

\section{Discussion}

The aim of this study was to examine the possible relation between religiosity, mental health, and psychological resilience on breast cancer patients. Our results indicated that psychological resilience has a beneficial effect on the mental health of breast cancer patients, while symptom burden can predict poor psychological wellbeing.

Assessment of religiosity and religious preferences in breast cancer patients can contribute to planning and implementing an individualised care plan based on the patient's values and preferences. Religion and faith were found to provide, in women diagnosed with breast cancer, appropriate tools for coping with their condition and should be recognised by health care professionals. In addition, it is very important to encourage patients to seek religion and support their religious service participation [24]. Previous research exploring the area of religiosity and mental well-being on breast cancer patients concluded that religiosity has a mediating role, and although it cannot predict a direct association with wellbeing, it can facilitate good adaptation to illness, especially in those who are classified as highly religious [25]. A German study indicated that religious commitment and religious coping was 

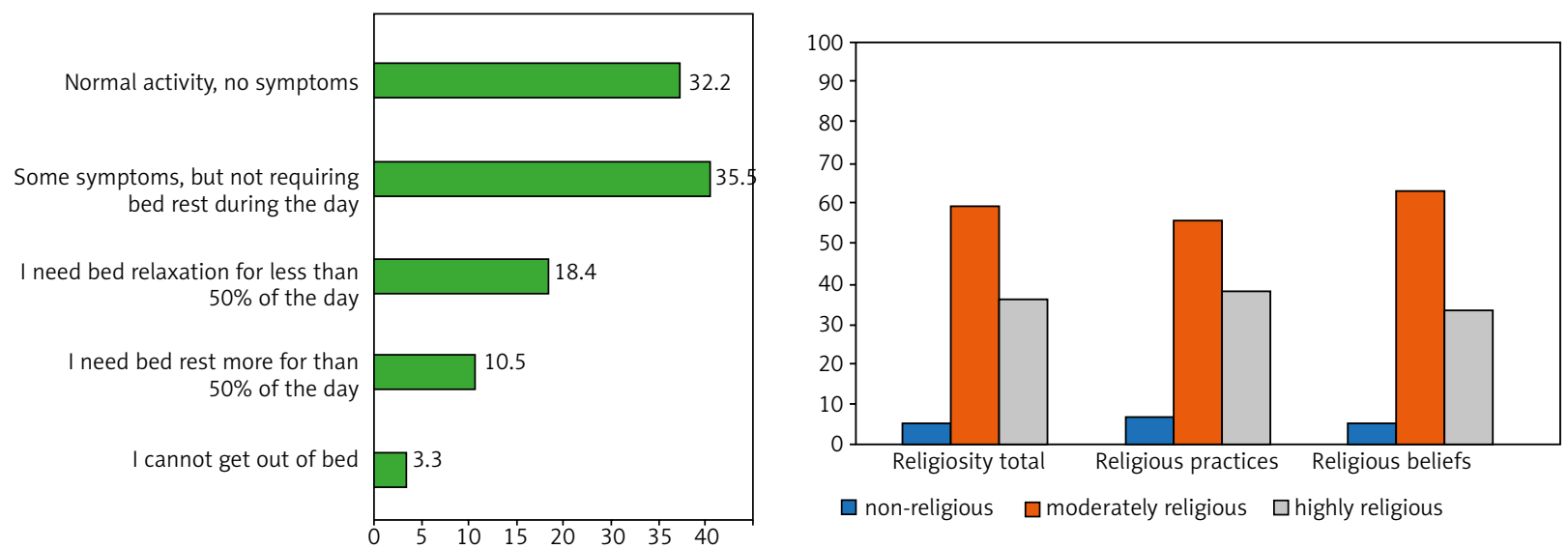

Fig. 1. Symptom burden of patients

Fig. 2. Centrality of religiosity scale

Table 2. Centrality of Religiosity Scale score between stage of cancer and type of surgery

\begin{tabular}{llllccc} 
Cancer stage and type & \multicolumn{2}{c}{ Religiosity total } & \multicolumn{2}{c}{ Religious practices } & \multicolumn{2}{c}{ Religious beliefs } \\
\cline { 2 - 7 } of surgery & Mean $( \pm)$ & $p$-value & Mean $( \pm)$ & $p$-value & Mean $( \pm)$ & $p$-value \\
Initial & $3.17(1.07)$ & 0.014 & $3.22(1.16)$ & 0.012 & $3.14(1.06)$ & 0.020 \\
Advanced & $3.60(1.03)$ & & $3.67(1.05)$ & & $3.54(1.05)$ & \\
Mastectomy & $3.66(0.85)$ & 0.001 & $3.74(0.89)$ & 0.001 & $3.61(0.87)$ & 0.001 \\
Lumpectomy & $2.80(1.27)$ & & $2.81(1.33)$ & & $2.78(1.26)$ &
\end{tabular}

Table 3. Correlation analysis between depression, anxiety, symptom burden, resilience, and religiosity

$\begin{array}{lcccc} & \text { Depression } & \text { Anxiety } & \text { Symptom burden } & \text { Resilience } \\ \text { Anxiety } & 0.733^{*} & & & \\ \text { Symptom Burden } & 0.238^{*} & 0.320^{*} & -0.411^{\star} & 0.194^{\star *} \\ \text { Resilience } & -0.414^{*} & -0.378^{*} & 0.015 & 0.213^{*} \\ \text { Religiosity total } & -0.075 & -0.086 & -0.026 & 0.176^{\star \star} \\ \text { Religious practices } & -0.083 & -0.083 & 0.043 & \end{array}$

$p<0.001, * * 0.05$ (two-tailed)

Table 4. Predicting factors for resilience among breast cancer patients

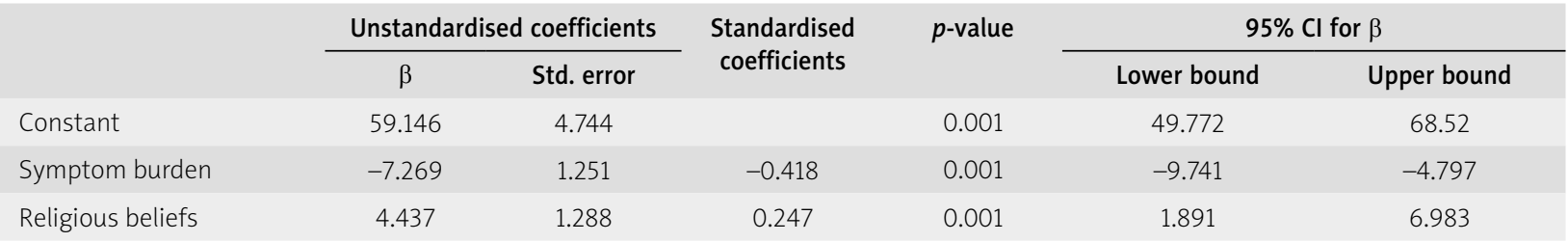

Table 5. Predicting factors for depression among breast cancer patients

\begin{tabular}{lllll} 
& \multicolumn{1}{c}{ OR } & p-value & \multicolumn{2}{c}{$95 \%$ Cl for EXP(B) } \\
\cline { 4 - 5 } & & & Lower & Upper \\
Resilience & 0.952 & 0.002 & 0.922 & 0.982 \\
Stage of cancer & 3.644 & 0.027 & 1.155 & 11.497 \\
Anxiety & 67.827 & 0.000 & 18.011 & 255.430 \\
Constant & 3.604 & 0.418 & &
\end{tabular}

Variable(s) entered: resilience, type of surgery, symptom burden, living arrangement, educational level, stage of cancer, anxiety
Table 6. Predictive factors of anxiety among breast cancer patients

\begin{tabular}{lcccc} 
& OR & p-value & \multicolumn{2}{c}{$95 \% \mathrm{Cl}$ for $\operatorname{EXP}(\mathrm{B})$} \\
\cline { 3 - 5 } & & & Lower & Upper \\
$\begin{array}{l}\text { Symptom } \\
\text { burden }\end{array}$ & 2.182 & 0.003 & 1.300 & 3.662 \\
$\begin{array}{l}\text { Depression } \\
\text { Constant }\end{array}$ & 67.324 & 0.000 & 19.806 & 228.840 \\
& 0.101 & 0.011 & &
\end{tabular}

Variable(s) entered: resilience, type of surgery, symptom burden, living arrangement, educational level, stage of cancer, depression 
not associated with psychosocial variables such as anxiety [26]. Similarly, another study failed to establish and prove a significant association between dispositional religious/ spiritual beliefs and emotional distress [27]. The above international studies' findings are in agreement with our results in which we did not find a direct association between religiosity and either depression or anxiety.

The increase of religious beliefs can have a positive effect and enhance resilience based on our results. Momeni et al. found a positive relationship between resilience and spirituality as well as predictive factors of quality of life [28]. Furthermore, Saeidi et al. reported that spiritual-religious intervention can have a positive effect on resilience, strengthening the assumption that there is a direct association between religiosity and spirituality and resilience [29]. An international study showed that religious beliefs and practice can have a positive effect on an individual's resilience [30].

One more notable finding of this study was the positive effect that resilience has on mental health, where psychologically resilient individuals experienced fewer depressive symptoms. In a recent Greek study, a similar finding was reported [3]. Also, international studies highlighted the negative relation between resilience and psychological distress [31-33].

According to our results, patients in end-stage cancer and those who had undergone mastectomy were more religious. End-stage cancer patients express various needs, such as spiritual and religious needs, especially during their final days of life. Many patients find comfort in believing in a collaboration with God to overcome illness [34] or to adapt to their illness. In a cross-sectional study in Greece it was reported that the majority of patients were engaged in private religious practices such prayers and were actively participating in their religious community. Although there was no association found between religiosity and psychological variables, the positive effect that religiosity had was found through the perceived social support that religious communities provide [35].

There are some limitations that merit consideration. First of all, our study is limited by a small sample size and by its cross-sectional nature, representing only one oncology hospital. The second limitation is that the majority of the population in Greece is orthodox, as was our sample. Therefore, it cannot be generalised to those belonging to other religious groups.

\section{Conclusions}

The results of this study provide evidence that religiosity and resilience are factors that contribute to enhancement in coping capacity and in maintaining mental health of breast cancer patients. In conclusion, providing adequate and satisfactory holistic care in which patients' values and religious preferences are integrated is suggested. To this end, it would be prudent for national surveys to include questions on religion and spirituality.

The authors declare no conflict of interest.

\section{References}

1. American Cancer Society. Global cancer Facts and Figures. American Cancer Society, Atlanta 2011.

2. Forouzanfar MH, Foreman KJ, Delossantos AM, Lozano R, Lopez AD, Murray CJL, Naghavi, M. Breast and cervical cancer in 187 countries between 1980 and 2010: A systematic analysis. Lancet 2011; 378: 1461-1484.

3. Fradelos EC, Papathanasiou IV, Veneti A, Daglas A, Christodoulou E, Zyga S, Kourakos M. Psychological Distress and Resilience in Women Diagnosed with Breast Cancer in Greece. Asian Pac J Cancer Prev 2017; 18: 2545-2550.

4. Ristevska-Dimitrovska G, Filov I, Rajchanovska D, Stefanovski P, Dejanova B. Resilience and Quality of Life in Breast Cancer Patients. Open Access Maced J Med Sci 2015; 3: 727-731.

5. Pieters H. "I'm Still Here” Resilience Among Older Survivors of Breast Cancer. Cancer Nurs 2016; 39: 20-28.

6. Alferi S, Culver J, Carver C, Arena P, Antoni M. Religiosity, Religious Coping, and Distress. J Health Psychol 1999; 4: 343-356.

7. Abou Kassm S, Hlais S, Khater C, et al. Depression and religiosity and their correlates in Lebanese breast cancer patients. Psychooncology 2018; 27: 99-105.

8. Unterrainer HF, Schoeggl H, Fink A, Neuper C, Kapfhammer HP. Soul darkness? Dimensions of religious/spiritual well-being among mood-disordered inpatients compared to healthy controls. Psychopathology 2012; 45: 310-316.

9. Khodaveirdyzadeh R, Rahimi R, Rahmani A, Ghahramanian A, Kodayari N, Eivazi J. Spiritual/Religious Coping Strategies and their Relationshipmwith Illness Adjustment among Iranian Breast Cancer Patients. Asian Pac J Cancer Prev 2016; 17: 4095-4099.

10. Atef-vahid M-K, Nasr-Esfahani M, Esfeedvajani MS, et al. Quality of life, religious attitude and cancer coping in a sample of Iranian patients with cancer. J Res Med Sci 2011; 16: 928-937.

11. Mesquita A, Chaves É, Avelino C, Nogueira D, Panzini R, Carvalho E. The use of religious/spiritual coping among patients with cancer undergoing chemotherapy treatment. Rev Lat Am Enfermagem 2013; 21: 539-545.

12. Kasen S, Wickramaratne P, Gameroff MJ, Weissman MM. Religiosity and resilience in persons at high risk for major depression. Psychol Med 2012; 42: 509-519.

13. Kim S, Esquivel GB. Adolescent spirituality and resilience: Theory, research, and educational practices. Psychol Sch 2011; 48: $755-$ 765.

14. Connor KM, Davidson JRT, Lee LC. Spirituality, Resilience, and Anger in Survivors of Violent Trauma: A Community Survey. J Trauma Stress 2003; 16: 487-494.

15. Arroll B, Goodyear-Smith F, Crengle S, Gunn J, Kerse N, Fishman T, Hatcher S. Validation of PHQ-2 and PHQ-9 to screen for major depression in the primary care population. Ann Fam Med 2010; 8: 348-353.

16. Kroenke K, Spitzer RL, Williams JB. The Patient Health Questionnaire-2: validity of a two-item depression screener. Med Care 2003; 41: 1284e1292.

17. Löwe B, Kroenke K, Grafe K. Detecting and monitoring depression with a two-item questionnaire (PHQ-2). J Psychosom Res 2005; 58: $163 e 171$.

18. Spitzer RL, Kroenke K, Williams JB, Lowe B. A brief measure for assessing generalized anxiety disorder: the GAD-7. Arch Intern Med 2006; 166: 1092-1097.

19. Kroenke K, Spitzer RL, Williams JBW, Monahan PO, Lowe B. Anxiety disorders in primary care: prevalence, impairment, comorbidity, and detection. Ann Intern Med 2007; 146: 317-325.

20. Connor KM, Davidson JRT. Development of a new resilience scale: the Connor-Davidson Resilience Scale (CD-RISC). Depress Anxiety 2003; 18: 76-82.

21. Windle G, Bennett KM, Noyes J. A methodological review of resilience measurement scales. Health Qual Life Outcomes 2011; 9: 8.

22. Huber S. The Centrality of Religiosity Scale (CRS). Religions 2012; 3: 710-724.

23. Fradelos EC, Kourakos M, Zyga S, Tzavella F, Tsaras K, Christodoulou E, Daglas A, Papathanasiou IV. Measuring Religiosity in Nursing: Reliability, Validity and Psychometric Properties of the Greek 
Translation of the Centrality of Religiosity Scale-15. Am J Nurs 2018; 7: 25-32.

24. Feher S, Maly R. Coping with breast cancer in later life: the role of religious faith. Psychooncology 1999; 8: 408-416.

25. Murken S, Mülle C, Huber S, Rüddel H, Körber J. The Role of Religion for Coping with Breast Cancer. Int I Behav Med 2004; 11 (Suppl): 332.

26. Zwingmann C, Müller C, Körber J, Murken S. Religious commitment, religious coping and anxiety: a study in German patients with breast cancer. Eur J Cancer Care (Engl) 2008; 17: 361-370.

27. Mehnert A, Rieß S, Koch U. [The role of religious beliefs in coping with malignant melanoma]. Verhaltenstherapie und Verhaltensmedizin 2003; 24: 147-166.

28. Momeni K, Shahbazi Rad A. Relationship of spirituality, resiliency, and coping strategies with quality of life in university students. J Behav Sci 2012; 6: 1-2.

29. Saeidi MS, Pour Ebrahim T, Bagherian F, Mansour L. [The relationship between spirituality and resilience of families, the quality of communication in family mediation]. J Manag Syst 2010; 2: 63-79.

30. Javanmard G. Religious Beliefs and Resilience in Academic Students. Procedia Soc Behav Sci 2013; 84: 744-748.

31. Matzka M, Mayer H, Köck-Hódi S, Moses-Passini C, Dubey C, Jahn P, Schneeweiss S, Eicher M. Relationship between resilience, psychological distress and physical activity in cancer patients: A cross-sectional observation study. PLoS ONE 2016; 11: 0154496.

32. Min JA, Yoon S, Lee CU, Chae JH, Lee C, Song KY, Kim TS. Psychological resilience contributes to low emotional distress in cancer patients. Support Care Cancer 2013; 21: 2469-2476.

33. Schumacher A, Sauerland C, Silling G, Berdel WE, Stelljes M. Resilience in patients after allogeneic stem cell transplantation. Support Care Cancer 2013; 22: 487-493.

34. Phelps AC, Maciejewski PK, Nilsson M, et al. Association between religious coping and use of intensive life-prolonging care near death among patients with advanced cancer. JAMA 2009; 301: 1140-1147.

35. Karaivazoglou K, Ifanti AA, Beratis I, Gerolymos M, Assimakopou los K, Iconomou HP, Kalofonos G, Iconomou G. Effect of social support and religiosity on psychological function of cancer patients receiving chemotherapy. Forum Clin Oncol 2007; 6: 189-195.

\section{Address for correspondence}

\section{Evangelos C. Fradelos}

Psychiatric Department

"Sotiria" Athens General Hospital for Chest Diseases

152 Mesogeion Ave.

11527 Athens, Greece

e-mail: evagelosfradelos@hotmail.com

Submitted: 1.09 .2018

Accepted: 11.09 .2018 